\title{
Automation of column-based radiochemical separations: a comparison of fluidic, robotic, and hybrid architectures
}

\author{
By J. W. Grate*, M. J. O’Hara, A. F. Farawila, R. M. Ozanich and S. L. Owsley \\ Pacific Northwest National Laboratory, P.O. Box 999, Richland, WA 99352, USA
}

(Received December 20, 2009; accepted in revised form November 12, 2010)

\section{Automation / Radiochemical separation / Ion exchange / Extraction chromatography / Robotic / Nuclear forensics}

Summary. Two automated systems have been developed to perform column-based radiochemical separation procedures. These new systems are compared with past fluidic column separation architectures, with emphasis on using disposable components so that no sample contacts any surface that any other sample has contacted, and setting up samples and columns in parallel for subsequent automated processing. In the first new approach, a general purpose liquid handling robot has been modified and programmed to perform anion exchange separations using $2 \mathrm{~mL}$ bed columns in $6 \mathrm{~mL}$ plastic disposable column bodies. In the second new approach, a fluidic system has been developed to deliver clean reagents through disposable manual valves to six disposable columns, with a mechanized fraction collector that positions one of four rows of six vials below the columns. The samples are delivered to each column via a manual 3-port disposable valve from disposable syringes. This second approach, a hybrid of fluidic and mechanized components, is a simpler more efficient approach for performing anion exchange procedures for the recovery and purification of plutonium from samples. The automation architectures described can also be adapted to column-based extraction chromatography separations.

\section{Introduction}

In the absence of a definitive gamma-ray signature from a radionuclide within its sample matrix - that enables nondestructive analysis without sample preparation - the determination of radionuclides still depends on destructive analysis. Moreover, due to interferences that exist in both radiometric and mass spectrometric detection approaches, destructive analysis requires separations [1-3]. While many separation approaches have been used in the past, including precipitations and liquid/liquid extractions, columnbased approaches dominate radiochemical separations today. These may entail anion exchange resins [4-6], solid phase extraction materials [7-9], or solvent-impregnated resins for extraction chromatography [10-13]. In addition to their efficiency and convenience in manual separations, column-based approaches lend themselves to automation by

\footnotetext{
*Author for correspondence (E-mail: jwgrate@pnl.gov).
}

fluidic and robotic automation approaches [14-18]. Nevertheless, such methods are not in widespread use. The bulk of the literature [16] currently describes fluidic approaches for delivering samples, wash solutions and eluents from a single sample into a column, and propelling them by positive pressure applied by the fluid drive (pump) at controlled flow rates and volumes. The automated separations in this format may deliver the separated radionuclide to a fraction collector or directly to a detector, typically either a flow through radiometric detector or an inductively coupled plasma mass spectrometry (ICP-MS) instrument [2, 3, 17, 19]. Although column switching techniques have been described for efficiently processing several samples in series using a fluidic system [20], the passage of the sample through the fluidic system connections presents opportunities for cross contamination between samples.

Automation provides opportunities to reduce labor, reduce costs, improve throughput, and improve the consistency with which tedious multistep procedures are carried out. In the event of a nuclear accident, or an intentional nuclear attack by terrorists or a nation-state, very large numbers of similar samples may require analysis. Existing networks of analytical laboratories could easily be overwhelmed. The development of replicable automated approaches would increase the surge capacity for radiochemical analysis. Our current efforts are focused on the development of automated radiochemical separation approaches in which all surfaces that contact the sample are disposable, and the systems for delivering clean reagents never touch the samples. In addition, we are focused on the development of workstations where several samples and columns are set up in parallel, and are then processed automatically. The methods being developed are applicable to a range of applications including bioassays, safeguards, and nuclear forensics. In bioassays, for example, cross contamination between one sample and another could lead to inappropriate medical response for a patient; use of disposables for patient samples and their analysis is well-known in medical technology. In nuclear forensics, inaccurate results could have international consequences. In applications such as these, even the appearance that a possibility of cross-contamination exists is unacceptable. In addition, we are interested in automating radiochemical separations for ultratrace levels of actinide isotopes that may be analyzed by methods such as ICP-MS or thermal ionization mass spectrometry (TIMS); cleanli- 
ness is of the highest importance to minimize backgrounds and drive down detection limits.

In this paper, we will briefly describe and contrast two new approaches we have developed for automated radiochemical separations that meet these objectives. In the first case, a commercial generalized liquid handling robot has been modified and customized to perform column separations. In the second case, a unique system has been designed and developed specifically for a radiochemical column separation procedure that combines features of fluidic methods with mechanized components for fraction collection, creating a hybrid system. A fluidic sequential injection chromatography system will be described first as background for comparison. This paper will be focused on describing mechanical designs and approaches for automated columnbased separations. The methods described are applicable to both column-based ion exchange and column-based extraction chromatography. An anion exchange procedure that is well known in radiochemistry for actinide separations will be used as an illustrative example.

\section{Fluidic separation systems: sequential injection chromatography}

A schematic diagram of a fluidic system for automating column-based separations is shown in Fig. 1, incorporating typical elements from published designs. A comprehensive presentation of fluidic systems with numerous figures has previously been published in reference [16]. In the design shown here, clean reagents are selected by the multiposition valve, aspirated into the holding coil, and then, after a change in valve position, propelled under positive pres-

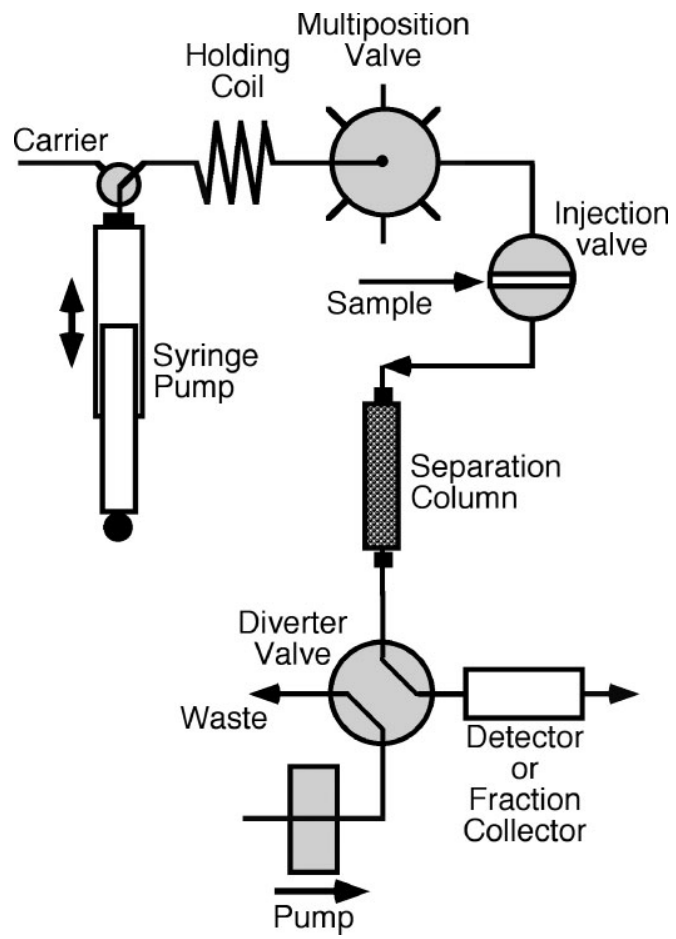

Fig. 1. Schematic diagram of a fluidic system for performing automated radiochemical separations by sequential injection chromatography. In this example, the sample is injected downstream from the reagent handling sequential injection system. sure to the column. This methodology for fluid delivery with reversible flow, a holding coil, and a mulitposition valve is called sequential injection. When used to deliver solutions for a column-based separation, it is called sequential injection chromatography. The sample may be introduced with a valve and sampling loop above the column, as shown in the figure, or aspirated and dispensed using the multiposition valve and the holding coil in the same manner as the clean reagents. A diverter valve below the column enables the column effluents to be directed to waste or to the analyte destination, which may be a detector or fraction collector. This diverter valve may also enable the delivery of solutions directly to the detector without going through the column, using the pump shown at the bottom of the figure.

Under preprogrammed control, the column may be preconditioned with reagents. Then the sample is delivered, followed by one or more eluent solutions. In this configuration, system and column wash steps are programmed after each sample separation to prevent or minimize carryover of one sample to the next. In some cases, systems have been developed that automatically release and replace the column separation material; retention on the separation material is where cross-contamination is most likely to occur [21]. Alternatively, in column-switching approaches [20], a multiposition valve can be used to direct a sample or eluents to one column of several arranged in parallel on the multiple valve ports.

In all these configurations, however, there will be some pathways that multiple samples will pass through, creating the possibility of cross-contamination from one sample to another. While studies have shown that such cross contamination can be minimized, to the point where it is insignificant relative to sample measurements, the possibility of cross contamination cannot be eliminated entirely in dedicated systems with continual reuse of flow pathways. For analytical applications where even the appearance of a possibility of cross-contamination is intolerable, we developed the additional automation approaches to be described below.

\section{Customized liquid handling robot}

In a robotic approach, we modified a commercial liquid handling system to perform column separations. In this approach, an $x-y-z$ translation head fitted with appropriate probes and tools can move samples and reagents from one place to another over a deck that has racks containing reagents, samples, separation columns, and supplies. A simplified schematic diagram is shown in Fig. 2. In this approach, the columns and collection vials are all disposable, and sample solutions are moved with disposable tips. Thus, no sample ever touches a surface that has been touched by another sample. Syringe pumps are connected to some of the probes in the $x-y-z$ translation head to aspirate and dispense liquids.

Our rationale for developing this approach was to start from a commercial liquid handling system and to customize it to meet the needs of radiochemical column separations. This appeared to be the most cost effective and expedient approach, at least initially. We specifically focused on developing a system to perform well-known actinide anion 


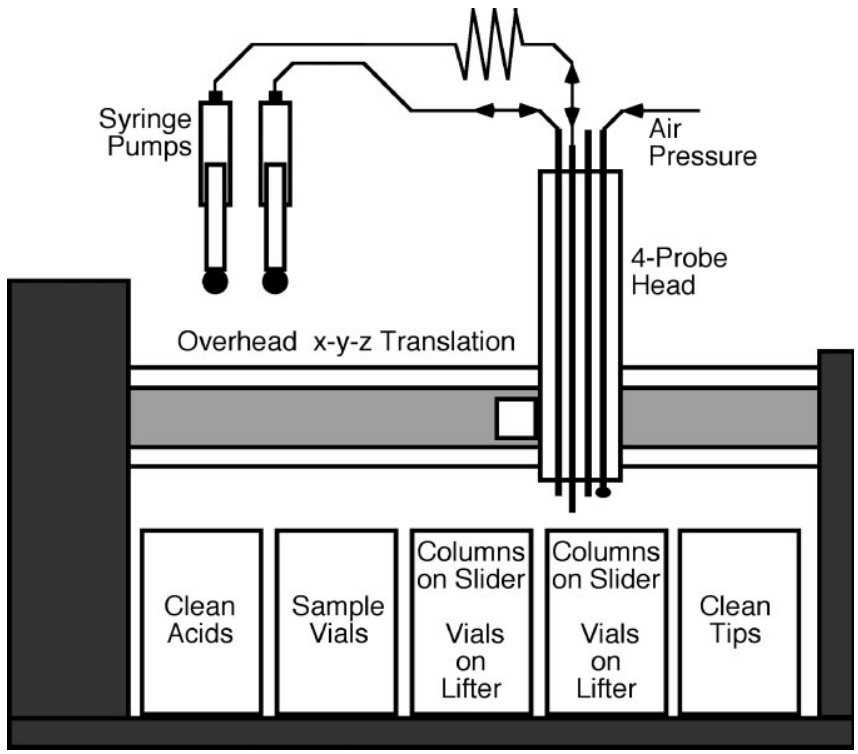

Fig. 2. Schematic diagram of the key components and layout of the Gilson liquid handling robot customized to perform column separations. The diagram does not show the tip disposal chute, the air pressure cleaning probe station, or the liquid probe(s) cleaning station. Components are not to scale.

exchange column separations, recognizing that the same or similar platform could also be set up and programmed to conduct extraction chromatographic separations.

In practice, selection and customization of a commercial system for the needs of radiochemistry was not trivial. The vast majority of such instruments are made for the biosciences and bioanalytical markets, where solutions are in $\mathrm{pH} 7$ buffer, or drug candidates are dissolved in noncorrosive organic solvents. The components are not designed to handle $7.5 \mathrm{M}$ nitric acid, $9 \mathrm{M}$ hydrochloric acid, or the resulting corrosive vapors. They are also typically used to manipulate much smaller solution volumes than is typical of a radiochemical separation using a $2 \mathrm{~mL}$ bed-volume column.

We developed an automated column-based separation system starting with the Gilson Quad-Z 215 liquid handler as our development platform. This system uses an overhead $x-y-z$ linear translation system to move a set of four probes above a deck (see Fig. 2). Racks on the deck of this system contain, from left to right, the clean reagent solutions, the sample vials, column holders and collection vials (two racks), and clean disposable tips. Additional stations are provided for disposing of used tips and washing the probes.

To perform column separations with fraction collection, the columns are placed in a rack with a plastic plate that suspends them above a fixed array of vials (see Fig. 3). This plate acts as a slider that can be moved forward or backward relative to the front of the rack, thus selecting which vials the columns drain into. A rod from the probe head can be lowered to engage the slider; in this arrangement, translation of the probe head also moves the slider and thus positions the columns. Each of the two slider racks are used to hold six columns in our procedure.

The receptacle vessels for the fractions were as follows for $2 \mathrm{~mL}$ (column bed) anion exchange columns: A) $50 \mathrm{~mL}$ polypropylene centrifuge tubes (for column condition/U elute and Th elute), B) $30 \mathrm{~mL}$ Teflon PFA vials (Sav-

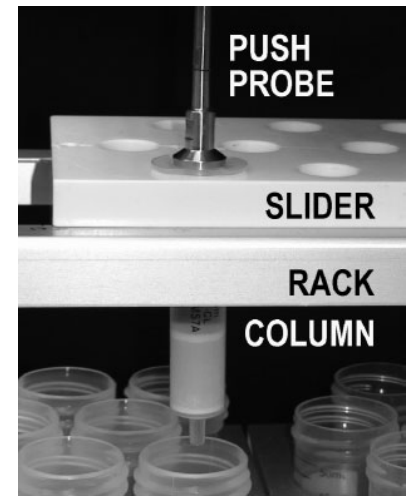

Fig. 3. Image of a column suspended above the collection vials, with the push probe for delivering air pressure in contact with the top column rim. This is a side view of the rack, with the front toward the left of the image. The vials are shown in the lowered position for clarity; normally during a push probe operation they would be raised up around the column bottoms.

illex, Minnetonka, $\mathrm{MN}$ ) for sample load and column rinse solution, and C) $30 \mathrm{~mL}$ Teflon PFA vials (Savillex) for $\mathrm{Pu} / \mathrm{Np}$ eluent solution. The columns were made from $6 \mathrm{~mL}$ polypropylene column tubes into which a $2 \mathrm{~mL}$ bed of $\mathrm{AG}$ 1-X4 resin (Eichrom Technologies, Inc.) had been packed. The system was also designed to perform separations using $0.1 \mathrm{~mL}$ column bed (AG 1-X4) separation columns, in which case $3 \mathrm{~mL}$ Savillex vials are used for fraction collection. The smaller columns were made from $1 \mathrm{~mL}$ column tubes.

The overhead probe system was customized to contain four different tools, in contrast to the conventional Quad$\mathrm{Z}$ with four identical fluid delivery probes. The customized probe head is shown in Fig. 4. The first probe on the left uses a $1 \mathrm{~mL}$ disposable tip to pick up sample from a sample vial and transfer it to the top of a column bed within the column body, thus loading the column. The disposable tips are automatically discarded and replaced between samples. The second probe is a tube can be inserted into a supply tank containing bulk reagents used as eluents, pull reagent solution into the probe and the holding coil tubing, and (after translation) deliver the reagent to the top of a column bed. This reagent probe never touches the samples or the column bodies, and it is washed in a cleaning station. Hence, it can be reused for each reagent and column. A third probe is a simple rod that fits into a hole on the column-holding slider, and then moves the columns above the array of collec-

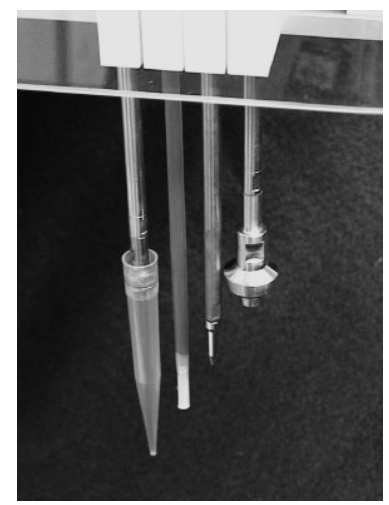

Fig. 4. Image of the 4-probe head. Probes are described in the text. 
tion vials, as discussed above. The fourth probe is designed to be lowered and pressed against the top of a column and then deliver pressurized air to drive each solution through the column bed by positive pressure. The top of the plastic column body has never been touched by the sample or eluent solutions, and a special cleaning station was developed that delivers wash solution and pressurized air to clean this probe between each use.

The disposable tip probe and the reagent delivery probe are connected to digital syringe pumps as shown in Fig. 2 . We used a holding coil filled with water, separated from reagents by an air segment, to avoid acid contact with valves and syringe pump. The probe for aspirating and delivering acid reagents is a carbon fiber reinforced Teflon probe from Elemental Scientific. The quantity of reagent delivered in one operation was limited to $3 \mathrm{~mL}$ by the volume available above the packed column in the $6 \mathrm{~mL}$ column tubes. The push probe was used to push this $3 \mathrm{~mL}$ through the column before additional reagent volume could be delivered.

Thus, the key features of this overall design with regard to the automation of column separations include the following: 1) Sample delivery to the columns is automated with the overhead $x-y-z$ system: samples are picked up in $1 \mathrm{~mL}$ disposable tips, moved to the columns, and dispensed into the columns by the liquid handler. 2) Solutions are delivered using the overhead $x-y-z$ system: solutions are aspirated into tubing by the reagent probe, moved to the columns, and dispensed into the columns by the liquid handler. 3) Solution movement through the column bed is accelerated using positive pressure delivered from above by a push probe that moves from column to column with wash steps in between. 4) And fraction collection of column effluents entails arrays of stationary collection vessels with columns that are translated in space above those collection vessels.

Four additional points deserve mention. 1) After dispensing a programmed volume of reagent, the software automat- ically directed the syringe pump to pull the solution remaining in the tip backward by a small volume, so that no drop is left hanging from the tip that might randomly drip off during translation movements. A similar procedure was used with solutions in the disposable tips. 2) A mechanical system (indicated as "lifter" in Fig. 2) was designed to sit beneath the fraction collection vials and raise (or lower) these vials in the $z$-direction. In the raised position, the tips of the columns were inside and surrounded by the vials; this prevented any spattering from the column outlets from escaping the collection vials and cross-contaminating the fractions. The vials were automatically raised and lowered during the procedure as needed to collect fractions (raised position) or to translate columns horizontally above the vials (lowered position) 3) A pressure feedback system was developed to determine when the pressurized air from the push probe had driven the solution in the column all the way through the column bed. This was accomplished by measuring the pressure of the air in the tubing above the push probe. The pressure dropped when the solution was all the way through the column. 4) Pressing the air push probe against the plastic column body rim in order to deliver pressure created the possibility that on raising the probe, the column would be attached and lifted with it. We instituted a procedure to raise the probe approximately $1.5 \mathrm{~cm}$, translate the probe horizontally back and forth a couple of times a distance of $\sim 5 \mathrm{~mm}$ each way, thus "wiggling" the probe and generating an angle between the long axis of the probe and the long axis of the column body. This would very effectively release the column in the event that the probe and column remained together following the pressurized air delivery step.

Software to run the system was based on Gilson's software for this platform, Trilution LH, with additional software routines added to accommodate custom hardware and procedures. Preprogrammed sequences of steps for the specific separations procedures were developed. The software

Table 1. Actinide anion exchange procedure using the customized Gilson robot.

\begin{tabular}{|c|c|c|c|c|c|}
\hline Purpose & $\begin{array}{l}\text { Reagent/ } \\
\text { sample }\end{array}$ & $\begin{array}{c}\text { Volume } \\
\text { (typical), } \mathrm{mL}\end{array}$ & $\begin{array}{l}\text { Collection } \\
\quad \text { vial }\end{array}$ & $\begin{array}{l}\text { Probe } \\
\text { used }^{a}\end{array}$ & Comment \\
\hline $\begin{array}{l}\text { Column } \\
\text { condition }\end{array}$ & $7.2 \mathrm{M} \mathrm{HNO}_{3}$ & 6 & A & 2 & $\begin{array}{l}\text { Delivered to column in } 2 \\
3 \mathrm{~mL} \text { portions }\end{array}$ \\
\hline Sample & Sample in & 6 & B & 1 & Delivered to column in 7 \\
\hline $\begin{array}{l}\operatorname{load}^{b} \\
\text { Sample }\end{array}$ & $\begin{array}{l}7.2 \mathrm{M} \mathrm{HNO}_{3} \\
7.2 \mathrm{MHNO}\end{array}$ & & & $2,1^{d}$ & $\begin{array}{l}1 \mathrm{~mL} \text { portions }{ }^{c} \\
\text { Delivered } 2 \mathrm{~mL} \text { aliquots }\end{array}$ \\
\hline $\begin{array}{l}\text { Sample } \\
\text { container } \\
\text { rinse }\end{array}$ & $1.2 \mathrm{M} \mathrm{HNO}_{3}$ & 6 & B & $2,1^{a}$ & $\begin{array}{l}\text { Delivered } 2 \mathrm{~mL} \text { aliquots } \\
\text { to sample container; } \\
\text { delivered } 21 \mathrm{~mL} \\
\text { portions to column; } \\
\text { repeat } 2 \times\end{array}$ \\
\hline $\begin{array}{l}\text { Wash, } \\
\text { U elution }\end{array}$ & $7.2 \mathrm{M} \mathrm{HNO}_{3}$ & 24 & A & 2 & $\begin{array}{l}\text { Delivered to column in } 8 \\
3 \mathrm{~mL} \text { portions }\end{array}$ \\
\hline Th elution & $9 \mathrm{M} \mathrm{HCl}$ & 9 & A & 2 & $\begin{array}{l}\text { Delivered to column in } 3 \\
3 \mathrm{~mL} \text { portions }\end{array}$ \\
\hline Pu elution ${ }^{e}$ & $1.2 \mathrm{M} \mathrm{HCl}$ & 12 & $\mathrm{C}$ & 2 & $\begin{array}{l}\text { Delivered to column in } 4 \\
3 \mathrm{~mL} \text { portions }\end{array}$ \\
\hline
\end{tabular}

a: In all cases, probe 4, "push probe" is used to pressurize the column to push solution through the packed bed after solution delivery.

b: Sample is typically iron hydroxide precipitate that has been dissolved in $6 \mathrm{~mL}$ of $7.2 \mathrm{M} \mathrm{HNO}_{3}$.

c: One extra $1 \mathrm{~mL}$ transfer is used to ensure that no droplets remain in the sample container.

d: System first uses probe 2 to deliver 7.2 $\mathrm{M} \mathrm{HNO}_{3}$ to sample container, then probe 1 (with fresh pipette tip) transfers rinse solution to the column.

e: Np likewise elutes in this step. 
successfully steps the components through all the steps of a conventional anion exchange column separation for actinides that isolates plutonium for mass spectrometric analysis. The column separation steps are described in Table 1.

Although ultimately capable of performing the desired column separation steps, the development of a system based on a general purpose liquid handling platform was lengthy, and resulted in a somewhat complex process with many movements. In addition, for a $2 \mathrm{~mL}$ column-bed separation process, the solution volumes involved require multiple trips to aspirate, translate, and dispense a sample or solution volume to the column.

\section{Hybrid fluidic/robotic radiochemical separation platform}

As an alternative approach, we developed a column separation system based on a set of stationary columns with an automated fluidic system to deliver the clean reagents to the column and propel them by positive pressure. The fractions are collected by moving an array of vials underneath the stationary columns using a mechanized fraction collector of our own design. It translates the array of vials horizontally in one direction (forward and back) to position a set of six vials beneath the six columns, and vertically to raise and lower the vials relative to the column tips (as discussed with regard to the Gilson liquid handing system above). Aside from the mechanized fraction collector, the only mechanical movements are the pumps and valves for propelling samples and reagents through tubing to the stationary columns. Thus, mechanized movement of samples, reagents, and columns through space is minimized in this approach. The overall system is shown in Fig. 5.

Image(s) of the fraction collector are shown in Fig. 6. The fraction collector system includes baffles that provide a barrier between the vials associated with each column; these provide a second level of protection against crosscontamination (where the first level of protection was provided by raising the vials up around the column tips by the fraction collector). The vials for fraction collection were: A) $15 \mathrm{~mL}$ polypropylene centrifuge tube that receives the initial column conditioning solution as well as the final DI water wash to clean the system post-analysis; B) $30 \mathrm{~mL}$ Savillex vial (same as Gilson) that recieves the sample and sample rinse solutions; C) $50 \mathrm{~mL}$ polypropylene centrifuge tube for the uranium elution and Th elution steps; and, D) $30 \mathrm{~mL}$ Savillex vial (same as Gilson) for the Pu-containing fraction.

The key challenges with this approach entail how to deliver the samples, protect the clean reagent delivery system from contamination, and ensure that all surfaces contacting the sample are disposable. In addition, we developed a new process for loading samples on the columns through disposable pathways and parts.

We set up a column assembly constructed entirely of disposable components, with two manual disposable valves placed immediately above the column. The lower manual valve is a 3 port valve that enabled delivery of samples to the top of the column without going through the reagent delivery system pathways. The 2 port manual valve above the 3 -port manual valve provides an additional degree of iso-

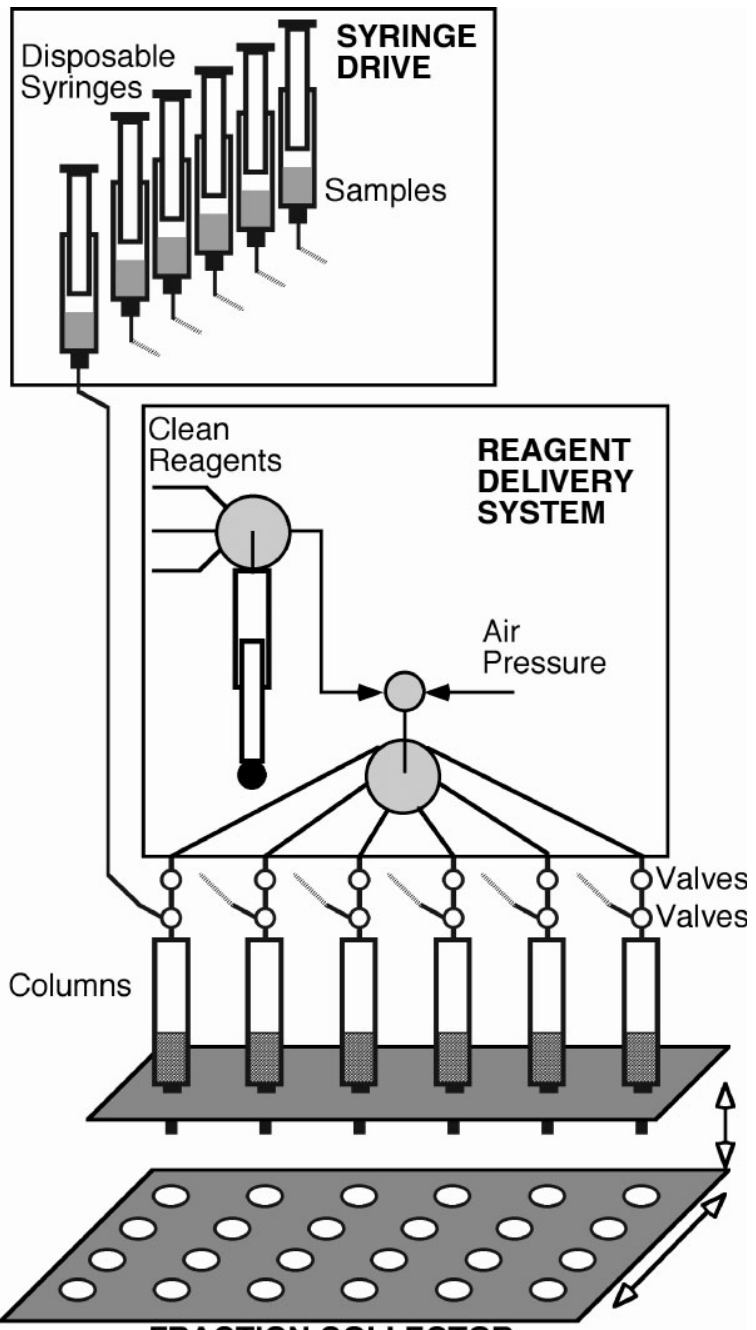

FRACTION COLLECTOR

Fig. 5. Pacific Northwest Extraction (PNX) system for column based separations. Samples only touch disposable components. A manual 3port disposable valve and a manual 2-port disposable valve above each column protect the clean reagent delivery system lines. Sample lines connect disposable sample-containing syringes to the 3-port manual valves above the columns; only one such line is shown in the diagram for clarity. Clean reagents are delivered using a zero dead volume valve with an integrated selection valve, and directed to particular columns using a subsequent multiposition valve. The pressurized air is supplied at ca. 5 psi.

lation between the sample-contacting components and the clean reagent delivery system upstream. The column assembly with the disposable manual valves is shown in Fig. 7.

At the onset of the automated separation routine, the clean reagent delivery system of the PNX, under software control, conditions the columns with 7.2 $\mathrm{M} \mathrm{HNO}_{3}$. Following this conditioning step, the software program prompts the analyst to confirm that samples are loaded and are ready for the sample load step to be initiated. The analyst loads the samples in the disposable $10 \mathrm{~mL}$ syringes and places these in the syringe drive. Sample lines from the syringes connect to the 3-port manual disposable plastic valves above each column, which is positioned to connect the sample line to the column. Thus, during sample load the port in the uppermost position on each of these valves (leading toward the reagent lines) is closed, protecting the upstream reagent lines. In addition, a 2-port manual disposable plastic valve is immediately upstream from the 3-port manual valve, and is 

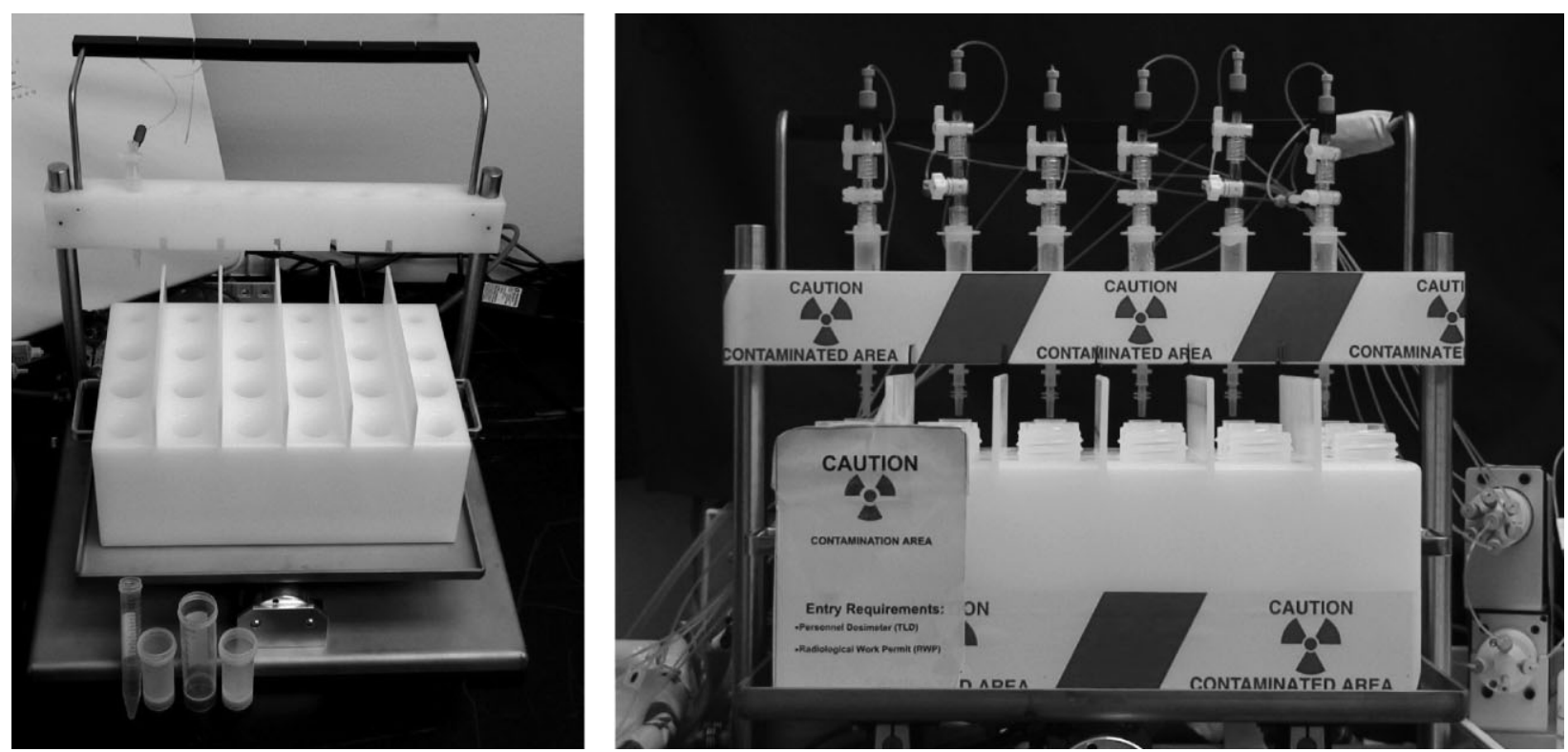

Fig. 6. Views of the mechanized fraction collection system and column holder, shown empty on the left and with columns and vials installed on the right.
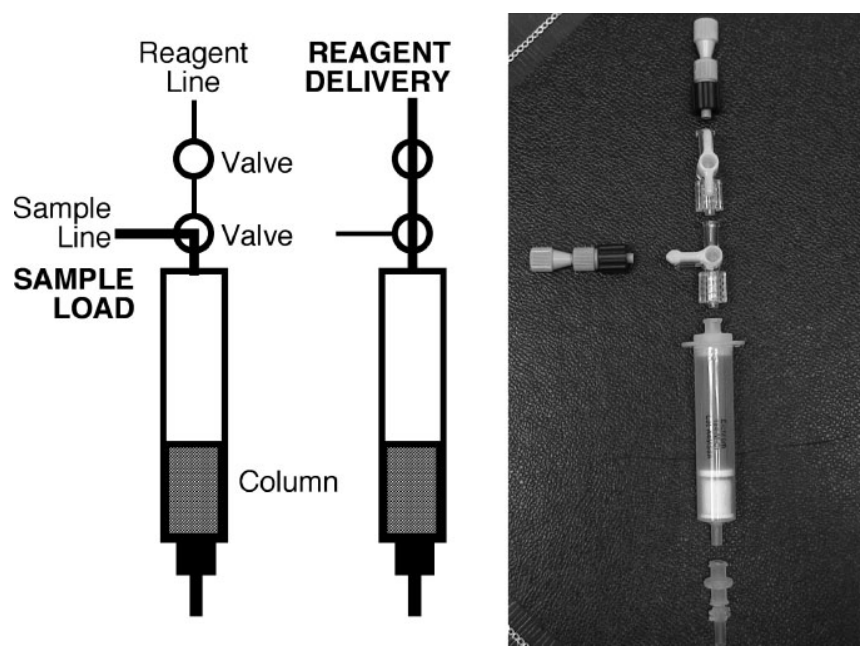

Fig. 7. Column assembly with disposable plastic manual valves above the column. In the schematic diagrams, the sample load pathway and the reagent delivery pathways are shown in bolder lines in the left and right columns, respectively.

also closed, providing a second level of protection to the upstream reagent lines. The syringe drive under software control propels all the samples onto the column in parallel. The analyst can manually add sample vessel wash solution to the syringes and reload them, if desired. When sample load is complete, the manual valves are both turned by the analyst to connect the reagent pathway to the column, preparing the system for delivery of the clean reagent solutions.

The automated reagent delivery is then started and proceeds to completion in coordination with the fraction collector. A selector valve at the head of the syringe pump selects which reagent acid is to be delivered to the columns. A multiposition valve selects the column to which the acid is delivered. The solution is delivered to all the columns in sequence. The system is also equipped with a source of pressurized air to drive each solution through each column to a vial in the fraction collector below. After each solution has been delivered to all columns and all columns have been
Table 2. Actinide anion exchange procedure using the PNX system.

\begin{tabular}{|c|c|c|c|}
\hline Purpose & Reagent/sample & $\begin{array}{c}\text { Volume } \\
\text { (typical), } \mathrm{mL}\end{array}$ & $\begin{array}{c}\text { Collection } \\
\text { vial }\end{array}$ \\
\hline $\begin{array}{l}\text { Column } \\
\text { condition }\end{array}$ & $72 \mathrm{M} \mathrm{HNO}_{3}$ & 6 & A \\
\hline Sample load & Sample in $7.2 \mathrm{M} \mathrm{HNO}_{3}$ & 6 & $\mathrm{~B}$ \\
\hline Wash & $7.2 \mathrm{M} \mathrm{HNO}_{3}$ & 4 & $\mathrm{~B}$ \\
\hline U elution & $7.2 \mathrm{M} \mathrm{HNO}_{3}$ & 28 & $\mathrm{C}$ \\
\hline Th elution & $9 \mathrm{M} \mathrm{HCl}$ & 12 & $\mathrm{C}$ \\
\hline Pu elution ${ }^{a}$ & $1.2 \mathrm{M} \mathrm{HCl}$ & 15 & $\mathrm{D}$ \\
\hline
\end{tabular}

a: Np likewise elutes in this step.

cleared by pressurized air, another solution is selected and delivered in a similar fashion, until the sequence of reagent solutions (eluents) is completed.

The fluidic components and the fraction collector are automated using software previously developed at PNNL in LabWindows / CVI, and modified to include operation of the fraction collector. It can automatically handle up to six columns set up in parallel. The PNX system works without difficulties and has proven to be exceptionally reliable. We have not recorded a single misfiring of the fraction collector, and it is not subject to positional errors. The fluidic system and the associated command software is also highly reliable. The PNX system is a rugged and reliable workhorse.

The anion exchange procedure demonstrated using the PNX system is detailed in Table 2. Samples spiked with plutonium were precipitated using a standard iron hydroxide method and redissolved for anion exchange separation. Analytical separation procedures and results will be described in greater detail in a subsequent paper.

\section{Discussion}

In this paper we have described new automated systems for setting up several samples and columns in parallel for ra- 
diochemical column-based separations, using conventional anion exchange as an example. The systems were designed such that all surfaces contacting sample solutions are disposable, and can be replaced between runs. We have shown that a general purpose liquid handling robotic system can be adapted to the needs of column-based separations at the $2 \mathrm{~mL}$ column bed volume scale. However, this approach was somewhat complex. Multiple transfers of each sample or reagent were necessary for each step, using a pick up, translate, and dispense approach. Hence, there are many movements of samples, reagents, and even the columns through space.

We have also designed and demonstrated a "purposebuilt" automated system for column-based separations as a single purpose workstation. This approach uses a fluidic system of a pump and three valves for automated delivery of column wash and eluent solutions, once the samples have been loaded. A system of disposable manual valves, disposable sample syringes, and a syringe drive are used to load the samples while protecting the clean reagent delivery system from contamination. In this approach, the delivery of solutions to the column by pressure driven flow through tubing is very efficient, and batches of samples can be processed more rapidly than with the liquid handling system. The columns are stationary.

The purpose-built PNX system is also space efficient, reliable, and simple. In this regard, it is more suitable for installation and long term use in fume hoods, glove boxes, and hot cells than more complex systems, such as the one developed from a general purpose liquid handling robot or systems based on robotic arms.

Acknowledgment. The authors would like to acknowledge Robert Widholm, Joan M. Stevens, and Tim Hegeman from Gilson Scientific who helped in the development of the columns separation platform based on the Gilson liquid handler. The authors gratefully acknowledge funding from the US Department of Energy, National Nuclear Security Administration's Office of Nonproliferation and Verification Research and Development (NA-22). A portion of this research was carried out in the William R. Wiley Environmental Molecular Sciences Laboratory, a US DOE scientific user facility operated for the DOE by PNNL. The Pacific Northwest National Laboratory is a multiprogram national laboratory operated for the US Department of Energy by Battelle Memorial Institute.

\section{References}

1. Bickel, M., Holmes, L., Janzon, C., Koulouris, G., Pilvo, R., Slowikowski, B., Hill, C.: Radiochemistry: inconvenient but indispensable. Appl. Radiat. Isot. 53, 5-11 (2000).

2. Lariviere, D., Taylor, V. F., Evans, R. D., Cornett, R. J.: Radionuclide determination in environmental samples by inductively coupled plasma mass spectrometry. Spectrochim. Acta B 61, 877-904 (2006).

3. Kim, C. S., Kim, C. K., Martin, P., Sansone, U.: Determination of $\mathrm{Pu}$ isotope concentrations and isotope ratio by inductively coupled plasma mass spectrometry: a review of analytical methodology. J. Anal. At. Spectrom. 22, 827-841 (2007).
4. Dai, M., Kelley, J. M., Buesseler, K. O.: Sources and migration of plutonium in groundwater at the Savannah River Site. Environ. Sci. Technol. 36, 3690-3699 (2002).

5. Dai, M. H., Buesseler, K. O., Kelley, J. M., Andrews, J. E., Pike, S., Wacker, J. F.: Size-fractionated plutonium isotopes in a coastal environment. J. Environ. Radioact. 53, 9-25 (2001).

6. Goutelard, F., Calmet, D., Thomas, S.: Determination of Pu isotopes at trace levels in environmental samples: radioisotopes and stable element evolution during the radiochemical method. Comparison of three radiochemical protocols. In: Environmental Radiochemical Analysis. (Newton, G. W. A., ed.) Royal Society of Chemistry, Cambridge UK (1999), pp. 97-110.

7. Izatt, R. M., Bradshaw, J. S., Bruening, R. L.: Accomplishment of difficult chemical separations using solid phase extraction. Pure Appl. Chem. 68, 1237-1241 (1996).

8. Izatt, R. M.: Review of selective ion separations at BYU using liquid membrane and solid phase extraction procedures. J. Incl. Phen. Mol. Rec. Chem. 29, 197-220 (1997).

9. Izatt, R. M., Bradshaw, J. S., Bruening, R. L., Bruening, M. L.: Solid Phase extraction of ions of analytical interest using molecular recognition technology. Am. Lab 26, 28c-28m (1994).

10. Cortina, J. L., Warshawsky, A.: Developments in solid-liquid extraction by solvent-impregnated resins. Ion Exch. Solvent Extr. 13, 195-293 (1997).

11. Dietz, M. L., Horwitz, E. P.: Novel chromatographic materials based on nuclear waste processing chemistry. LC-GC 11, 424-436 (1993).

12. Horwitz, E. P., McAlister, D. R., Dietz, M. L.: Extraction chromatography vs. solvent extraction: how similar are they? Sep. Sci. Technol. 41, 2163-2182 (2006).

13. Dietz, M. L., Horwitz, E. P., Bond, A. H.: Extraction chromatography: progress and opportunities. ACS Symp. Ser. 716, 234-250 (1999).

14. Grate, J. W., Egorov, O. B.: Automated radiochemical separation, analysis, and sensing. In: Handbook of Radioactivity Analysis. $2^{\text {nd }}$ Edn. (L'Annunziata, M. F., ed.) Academic Press, San Diego (2003), pp. 1129-1164.

15. Grate, J. W., Egorov, O. B.: Automating analytical separations in radiochemistry. Anal. Chem. 70, 779A-788A (1998).

16. Grate, J. W., Egorov, O., O’Hara, M. J.: Automation of extraction chromatographic and ion exchange separation methods for radiochemical analysis and monitoring. In: Ion Exchange and Solvent Extraction. (Moyer, B., ed.) CRC Press, Boca Raton, FL (2010), pp. 515-562.

17. Lariviere, D., Whyte, J. C., Zhang, W., Hoffman, I., Ungar, R. K., Johnson, S., Cornett, R. J.: Rapid and automated analytical technologies for radiological/nuclear emergency preparedness. In: $\mathrm{Nu}$ clear Chemistry: New Research. (Koskinen, A. N., ed.) NOVA Publishers, Hauppauge NY (2008), in press.

18. Beugelsdijk, T. J., Hollen, R. M.: Robotics and automation in radiochemical analysis. In: Handbook of Radioactivity Analysis. $1^{\text {st }}$ Edn. (L'Annunziata, M. F., ed.) Academic Press, San Diego, CA (1998), pp. 693-718.

19. Egorov, O. B., O'Hara, M. J., Farmer III, O. T., Grate, J. W.: Extraction chromatographic separations and analysis of actinides using sequential injection techniques with on-line inductively coupled plasma mass spectrometry (ICP MS) detection. Analyst 126, 1594-1601 (2001)

20. Grate, J. W., Fadeff, S. K., Egorov, O.: Separation-optimized sequential injection method for rapid automated separation and determination of ${ }^{90} \mathrm{Sr}$ in nuclear waste. Analyst 124, 203-210 (1999).

21. Egorov, O., O’Hara, M. J., Grate, J. W., Ruzicka, J.: Sequential injection renewable separation column instrument for automated sorbent extraction separations of radionuclides. Anal. Chem. 71, 345-352 (1999). 